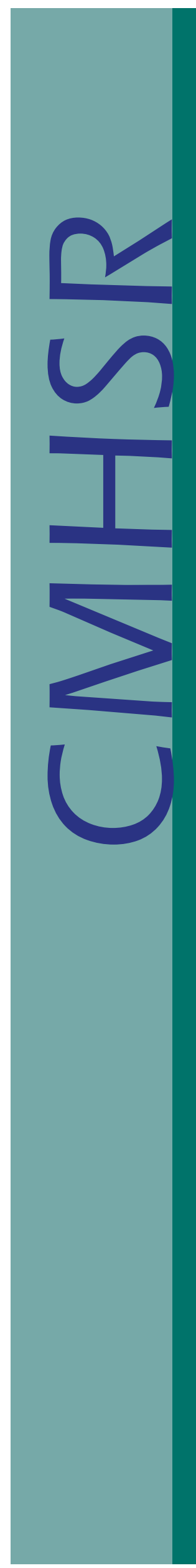

\title{
Mothers with Mental Illness who are Childhood Trauma Survivors: Implications for Policy and Practice
}

Joanne Nicholson, Ph.D. and Karen Albert, M.S.

\section{$\mathrm{L}$} ong-term effects of childhood victimization may be devastating, even for resilient women. Abusive relationships are characterized by feelings of betrayal and powerlessness, and violation of physical and emotional boundaries. Abuse survivors may reconstruct reality to reconcile expectations or wishes about how life should be. ${ }^{1,2}$ Women's willingness and ability to form positive, healthy relationships in the present, including relationships with children and treatment providers, may be affected by their early histories of violence and trauma.

Childhood violence has been associated with the development of later psychopathology. In a recent study of patients with chronic major depression, 45\% experienced childhood physical abuse, 16\% experienced childhood sexual abuse, and 10\% experienced neglect. ${ }^{3}$ Many symptoms women develop in response to trauma, whether they are ultimately categorized and labeled as Posttraumatic Stress Disorder, Major Depression, or Anxiety Disorders, may be reframed as "coping mechanisms." These strategies allow children and, ultimately, the women they become, to survive, physically and emotionally, even though

Mothers want to behave in a trustworthy manner with their children. these coping mechanisms may be unhealthy or expose them to further risk. Women whose dissociation served to remove them from the pain of on-going abuse as a child may have difficulty being present in relationships they desire or would benefit from as adults. Women's ability to parent, e.g., to form positive bonds with children, organize their day-to-day activities, and manage children's behavior, may be affected by the nature and extent of the violence they have experienced. ${ }^{4}$ However, the exact contribution of childhood histories to later parenting behavior is unclear.

C 2004 Center for Mental Health Services Research Department of Psychiatry University of Massachusetts Medical School

\section{Mothers Describe Their Experiences}

Researchers at the Center for Mental Health Services Research conducted focus groups with 44 mothers with mental illness (MI) across Massachusetts. ${ }^{5}$ Participants identified key parenting issues related to their experiences of childhood violence and trauma:

- Trust. Participants report difficulty trusting in their ability to parent and their judgments about their children's needs, and in trusting others to care appropriately for their children when they cannot. As one mother explains, "How do I know this person will care for my baby? What if they don't take proper care?" Mothers want to behave in a trustworthy manner with their children.

- Safety. Mothers worry about how to keep themselves and their children safe. They acknowledge that their ability to provide a safe environment may be compromised by their mental illness. Others describe the difficulty when partners are abusive. "...I couldn't protect and defend my kids against my husband. I couldn't even do it for myself..." Unfortunately, stigma associated with mental illness may interfere with mothers' efforts on behalf of their children. One mother explained, "...when my children were being abused, they were saying 'mommy, please help me'...and everyone just ignored what I said because of the mental illness."

- Power and control. Empowerment is a key aspect of recovery for women with histories of childhood trauma and mental illness. Issues of power and control are particularly salient in parent-child relationships and in dealing with the demands of others, such as school teachers, pediatricians, treatment providers, etc. One mother states: "...I think you need to know your limits...have a plan set up for if you do get sick...a place that your kids can go..." 
- Availability. Mothers understand "...you need to be there for your kids..." emotionally as well as physically. Mothers whose symptoms are triggered by current events may be compromised in their ability to be available to meet their children's needs. Fortunately, the desire for close relationships with children may motivate mothers to make progress in their recoveries. "...I know that I want to get better. I know that I can only show my children today that I am trying my best."

- Guilt and shame. Mothers explain that negative feelings about one's self may translate into negative feelings about one's children and one's ability to parent. Mothers describe feeling "...selfish and guilty...that you're not the perfect parent...that you don't stop and think about them (children) when you are trying to hurt yourself..." Mothers experience their parenting "failures" keenly. As one mother said, "And when they say, 'We're taking what you have left, that's keeping you alive' what do you think then? You figure you're a failure completely. You can't even take care of your own children. What's the sense in living?"

\section{Implications for Policy and Practice}

Policymakers and providers must review and revise their procedures and practices with mothers who are trauma survivors. This often requires a paradigm shift on the part of professionals to a trauma-informed way of working. Routine policies and practices, if not carefully considered in light of women's trauma experiences, may re-traumatize mothers, contributing to their distress rather than alleviating their concerns and facilitating their recovery. Suggestions for policymakers and providers include:

\section{- Question your professional and personal} assumptions. Don't assume that mothers who are trauma survivors will inflict trauma on their own children. Validate mothers' experiences and ask about their goals as parents as first steps in building trust.

- Consider the language you use. Symptoms may be mothers' coping mechanisms; manipulation or "working the system" may be how mothers insure survival for themselves and their children. Mothers viewed as treatment resistant or non-compliant may actually be prioritizing their parenting responsibilities when there are scheduling conflicts.

- Provide and participate in training to support mothers who are trauma survivors. Perhaps the best trainers are mothers who are trauma survivors themselves.
Their voices are often more powerful than those of the most accomplished professionals.

- Revise procedures and forms. Include questions about experiences of trauma, parenting, and relationships with children. Provide opportunities for mothers to identify their strengths as well as their children's strengths.

- Integrate services. Dedicate time for team and collateral contacts. Fragmented, undependable care impedes mothers' recoveries and contributes to negative outcomes for their children.

- Address the vicarious traumatization of staff. Staff benefit from opportunities to support each other, and suggestions for self-care strategies.

\section{Future Research}

Resilience and recovery are key in future studies of mothers with histories of violence and their children. Factors contributing to mothers' successes, and the health and well-being of their children must be identified and incorporated into treatment development efforts. Research is needed to identify correlates of and supports for healthy parenting for women with abuse and trauma histories.

\section{References}

1. Harris, M., Fallot, R.D. (Eds). (2001). Using trauma theory to design service systems. San Francisco, CA: JosseyBass.

2. Everett, B. \& Gallop, R. (2001). The link between child hood trauma and mental illness. Thousand Oaks, CA: Sage Publications.

3. Nemeroff, C.B., Heim, C.M., Thase, M.E., et al. (2003). Differential responses to psychotherapy versus pharma cotherapy in patients with chronic forms of major depression and childhood trauma. PNAS, 100(24),1429314296. www.pnas.org/cgi/doi/10.1073/pnas.2336126100

4. Hall, L.A., Sachs, B., \& Rayens, M.K. (1998). Mothers' potential for child abuse: the roles of childhood abuse and social resources. Nursing Research, 47(2), 87-95.

5. Nicholson, J., Sweeney, E.M., \& Geller, J.L. (1998).

Mothers with mental illness: I. The competing demands of parenting and living with mental illness. Psychiatric Services, 49, 635-642.

Visit us on-line at www.umassmed.edu/cmhsr 